\title{
USO DE IMAGENS DIGITAIS PARA AVALIAÇÃO DE PLÂNTULAS DE FEIJÃO ${ }^{1}$
}

\author{
LUCIO ZABOT ${ }^{2}$, LUIZ MARCELO COSTA DUTRA ${ }^{3}$, NILSON LEMOS DE \\ MENEZES ${ }^{3}$, DANTON CAMACHO GARCIA ${ }^{3}$, MARCOS PAULO LUDWIG ${ }^{4}$, \\ VALDECIR JOSÉ DOS SANTOS ${ }^{5}$
}

\begin{abstract}
RESUMO - Com o objetivo de observar o crescimento inicial de feijão, utilizando a avaliação de plântulas por meio de imagens digitais, processadas pelo programa Sigma Scan Pro v. 5.0 e pelo método tradicional de laboratório, foi conduzido o experimento avaliando a influência da temperatura, das cultivares e de diferentes lotes de sementes de feijão (Phaseolus vulgaris L.). O experimento foi conduzido em câmaras climatizadas no Laboratório Didático e de Pesquisas em Sementes do Departamento de Fitotecnia - UFSM, onde foram utilizadas as temperaturas constantes de 10, 15, 20, 25 e $30^{\circ} \mathrm{C}$, as cultivares Valente e Uirapuru e quatro lotes com diferentes níveis de qualidade fisiológica, obtidos por meio de envelhecimento acelerado durante períodos de zero, 12, 24 e 36 horas $\left(41^{\circ} \mathrm{C}\right.$ e $100 \%$ de UR do ar). A captação de imagens ocorreu concomitantemente à avaliação visual do crescimento das plântulas, utilizando câmera digital (Sony ${ }^{\circledR} 3.2 \mathrm{mp}$ ). O delineamento experimental utilizado foi inteiramente ao acaso, com quatro repetições e 10 amostras. Os testes realizados foram: comprimento do hipocótilo e da raiz primária de plântulas normais, por meio do método tradicional e da coleta de imagens digitais das mesmas plantas. A partir dos resultados pode-se considerar que as avaliações de crescimento das plântulas por meio da análise de imagens digitais e pelo procedimento tradicional apresentam resultados semelhantes e são eficientes para a avaliação do vigor de sementes de feijão.
\end{abstract}

Termos para indexação: Imagens digitais, hipocótilo, raiz, temperatura.

\section{USE OF DIGITAL IMAGES TO EVALUATE FIELD BEAN SEEDLING GROWTH}

\begin{abstract}
Methods of determining initial growth of field bean seedlings are important to determine seed vigor. A laboratory experiment was carried out with the objective of determining initial bean (Phaseolus vulgaris L.) seedling growth using digital images compared to traditional laboratory tests using two cultivars each represented by four seed lots of different physiological quality germinated at different temperatures. The digital images were processed using the Sigma Scan Pro v. 5.0 software. Temperatures used were 10, 15, 20, 25 and $30^{\circ} \mathrm{C}$, the cultivars 'Valente' and 'Uirapuru' and four seed lots of each cultivar with different physiological characteristics obtained by artificial aging periods of zero, 12, 24 and 36 hours at $41 \mathrm{C}$ and $100 \%$ relative humidity. Images were captured by digital camera (Sony ${ }^{\mathrm{TM}} 3.2 \mathrm{mp}$ ). A randomized complete block experimental design was used with four replicates. Tests included: hypocotyl and root length evaluated by the traditional method and digital imaging. Results showed comparable efficiency of both to determine field bean initial seedling growth.
\end{abstract}

Index terms: Digital imaging, hypocotyl, root, temperature.

${ }^{1}$ Submetido em 17/10/2007. Aceito para publicação em 22/07/2008. Parte da Dissertação de Mestrado do primeiro autor, apresentada ao Programa de Pós-graduação em Agronomia (PPGA), Universidade Federal de Santa Maria (UFSM). ${ }^{2}$ Eng. Agr., M.Sc., Doutorando do PPGA/UFSM. Departamento de Fitotecnia, Universidade Federal de Santa Maria,
Av. Roraima, 1000, Cidade Universitária, Bairro Camobi, CEP 97105900. E-mail: luciozabot@yahoo.com.br. ${ }^{3}$ Eng. Agr., Dr. Professor do Departamento de Fitotecnia, UFSM. ${ }^{4}$ Eng. Agr., Mestrando do Programa de Pós-graduação em Sementes, Universidade Federal de Pelotas (UFPel).

${ }^{5}$ Eng. Agr., Mestrando do PPGA/UFSM. 


\section{INTRODUÇÃO}

O feijoeiro comum (Phaseolus vulgaris L.) é uma espécie amplamente difundida e cultivada em todos os Estados brasileiros, sendo parte incondicional da dieta humana (JAUER et al., 2004). No Rio Grande do Sul, é caracterizado pelo cultivo em pequenas propriedades e pela possibilidade de semeadura em mais de uma época, o que contribuiu para o crescimento em importância desta cultura no contexto agrícola do Estado, onde é semeado tradicionalmente em duas épocas: a primeira, conhecida como safra (semeada entre agosto e outubro) e a segunda, conhecida como safrinha (semeada em janeiro e fevereiro), segundo ZABOT et al. (2004).

Em Regiões com temperaturas reduzidas no inverno, a germinação constitui uma fase crítica para o estabelecimento do feijoeiro. Esta limitação se deve, principalmente, à lentidão do processo de germinação (SIQUEIRA et al., 1995). A temperatura mínima, para a germinação e emergência de plântulas de feijão é distinta, sendo que para aquela, a temperatura varia de 7 a $10,3^{\circ} \mathrm{C}$, ocorrendo variações dentro da espécie. Em temperaturas constantes e inferiores a $11^{\circ}$ $\mathrm{C}$, o feijoeiro consegue emitir raiz, rompendo o tegumento, porém não consegue emergir do solo (ROEGGEN, 1987).

Estas situações fazem com que testes de vigor baseados na avaliação de plântulas em condições de campo, ou mesmo em laboratório, simulando as dificuldades previstas para o desenvolvimento inicial da cultura em campo, forneçam indicações da potencialidade de cultivares e lotes, uma vez que as diferenças existem e as respostas de ambos podem ser variáveis em função das condições da estação de crescimento (NAKAGAWA, 1994).

Conduzidos de maneira similar ao teste de padrão de germinação, as avaliações de plântulas buscam evidenciar a qualidade fisiológica de sementes, quanto à manifestação de seu vigor. A determinação do comprimento médio das plântulas normais ou de suas partes, como raiz primária ou hipocótilo, são procedimentos que, em função da morosidade, provocam a falta de padronização na determinação dos parâmetros, sendo desta maneira, de menor confiabilidade (TEIXEIRA, 2004).

O vigor de um lote de sementes não é determinado por apenas uma característica em particular, mas por um conjunto delas, associadas ao desempenho das sementes. É pouco provável que apenas um teste, como por exemplo, o padrão de germinação seja suficiente para diferenciar, com segurança, o potencial de desempenho de lotes de sementes (CUSTÓDIO, 2005).
Recentemente, segundo TEIXEIRA (2004), métodos digitais têm sido propostos com base na avaliação do comprimento de partes de plântulas para várias culturas, tais como soja, alface, cenoura e beterraba, sempre na tentativa de padronização e busca de precisão nos resultados.

Neste sentido, a busca de avaliações de plântulas através de programas computadorizados e com maior precisão seria uma alternativa para a indústria de sementes bem como para laboratórios, onde a coleta de dados fotográficos e seu posterior processamento registrariam dados precisos e com informações importantes a respeito do comportamento das plântulas e, consequentemente, seriam um indicativo de qualidade fisiológica de lotes ou cultivares diferenciadas.

O objetivo do presente trabalho foi avaliar o vigor de sementes de feijão por meio de análise de imagens digitais processadas pelo programa Sigma Scan Pro v. 5.0, Jandel Scientific e pelo método de mensuração tradicional de laboratório.

\section{MATERIAL E MÉTODOS}

O experimento foi conduzido no Laboratório Didático e de Pesquisas em Sementes do Departamento de Fitotecnia, da Universidade Federal de Santa Maria, em Santa Maria RS. Foram utilizadas sementes de duas cultivares de feijoeiro comum, 'Valente' e 'Uirapuru' (ambas classificadas como tipo II e grupo comercial preto), dividas em quatro lotes de diversos níveis de qualidade fisiológica, diferenciados pelo envelhecimento acelerado por períodos distintos, e submetidas à germinação nas temperaturas constantes de $10,15,20,25$ e $30^{\circ} \mathrm{C}$. As sementes foram produzidas na safra agrícola 2005/2006 e adquiridas junto à Cooperativa Agrícola Mista Comacel, de Arroio do Tigre - RS.

Para a obtenção dos lotes por meio do envelhecimento artificial, as sementes de cada cultivar foram acondicionadas em bandejas de fundo metálico telado e envelhecidas em câmara de envelhecimento acelerado por períodos de zero, 12,24 e 36 horas (lotes 1, 2, 3 e 4 , respectivamente) a $41^{\circ} \mathrm{C}$ e $100 \%$ de umidade relativa do ar.

A determinação do grau de umidade inicial foi realizada pesando aproximadamente cinco gramas de sementes de cada lote, com quatro repetições, mantidas em estufa por 24 horas e temperatura constante de $105 \pm 3^{\circ} \mathrm{C}$ (BRASIL, 1992). Os valores obtidos não ultrapassaram 13,0\%, conforme recomendou MARCOS FILHO (1994), não sendo necessários ajustes no teor de água para realização dos testes e garantindo que este fator não influenciasse nos resultados das avaliações posteriores. 
Na avaliação do crescimento de plântulas por meio do método tradicional foram utilizadas quatro repetições de 20 sementes para todos os tratamentos, sendo a semeadura no terço superior do papel umedecido, com água destilada, no volume de 2,5 vezes a massa do papel seco. Os rolos contendo as sementes foram mantidos em germinadores por oito dias, sob as temperaturas constantes previstas no trabalho. No oitavo dia, as plântulas foram aleatoriamente separadas em quatro repetições de 10 plântulas para cada lote, sendo estas submetidas às avaliações (NAKAGAWA, 1994).

Para obtenção dos dados de comprimento de hipocótilo foram realizadas as medidas da região de diferenciação entre raiz/hipocótilo até os cotilédones e, para a mensuração da raiz foi considerado o comprimento da raiz primária, utilizando-se régua com graduação em milímetros (mm). Os comprimentos, tanto de hipocótilo como de raiz primária, foram formados a partir da média das 10 plântulas avaliadas e expressos em centímetros $(\mathrm{cm})$.

Para a determinação das leituras pelo método de imagens digitais, as mesmas plântulas utilizadas no método tradicional foram dispostas em uma base fotográfica de cor preta, medindo $50 \times 40 \mathrm{~cm}$, que continha no sentido vertical e horizontal linhas referenciais milimetradas para a calibração do programa de processamento das imagens. As plântulas foram criteriosamente dispostas evitando ao máximo a interposição das partes a serem mensuradas, fazendo com que as mesmas estivessem paralelas à linha referencial milimetrada vertical e, também, completamente em contato com a base fotográfica, minimizando erros de leitura no processamento.

A câmera fotográfica digital utilizada foi Sony ${ }^{\circledR}$, modelo Cybershot Smart, DSC - p72, 3.2 Megapixels, posicionada em Aparelho Fotográfico para Reprografia, distante $32 \mathrm{~cm}$ da base fotográfica (distância padrão para todas as imagens). As imagens coletadas foram processadas pelo programa Sigma Scan Pro v. 5.0, Jandel Scientific.

O delineamento experimental utilizado foi inteiramente ao acaso com quatro repetições, utilizando duas cultivares (Valente e Uirapuru), quatro níveis de qualidade fisiológica das sementes (zero, 12, 24 e 36 horas de envelhecimento artificial) e cinco temperaturas para germinação $(10,15,20$, 25 e $30^{\circ} \mathrm{C}$ ).

A análise estatística dos resultados foi realizada utilizando o Software Sistema de Análises Estatísticas - SANEST (ZONTA et al., 1986). As variáveis foram submetidas à análise da variância e em função das significâncias dos efeitos principais e das interações, foram comparadas pelo teste de Tukey em nível de $5 \%$ de probabilidade de erro ou regressão polinomial (STORCK et al., 2006) e os métodos utilizados (imagens digitais e laboratório) foram correlacionados no nível de de significância de $5 \%$.

\section{RESULTADOS E DISCUSÃO}

Na figura 1 observa-se o aspecto de algumas plântulas amostradas aleatoriamente entre os lotes utilizados.

FIGURA 1. Amostra das plântulas da cultivar Valente (1), para cada uma das temperaturas testadas, 10 (A), 15 (B), 20(C), 25 (D) e $30^{\circ} \mathrm{C}$ (E) e para a cultivar Uirapuru (2) nas temperaturas testadas, 10 (A), 15 (B), 20(C), 25 (D) e 30 ${ }^{\circ}$ C (E). Santa Maria/RS, 2006.

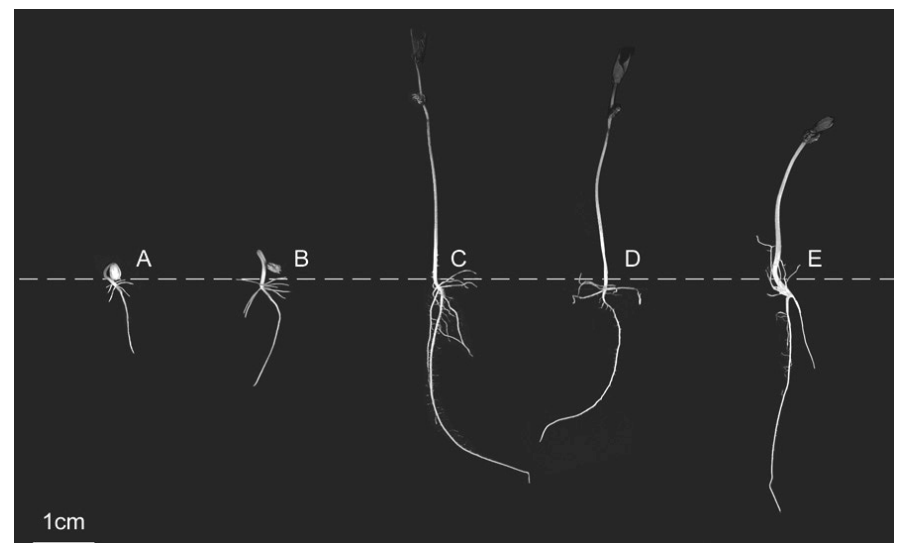

1

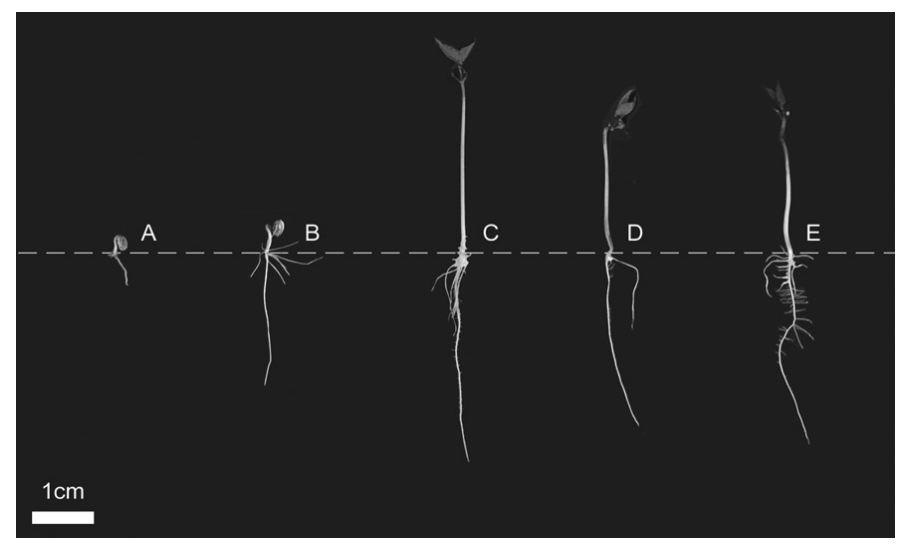

2 
A utilização de imagens digitais é uma ferramenta de fácil aplicação, sendo possível a captação de várias imagens em tempo relativamente reduzido, para posterior processamento com o auxílio de programas específicos de leitura de imagens. VOOREN \& HEIJDEN (1993) utilizaram imagens digitais para mensurar órgãos de plantas, assim como GUNASEKARAN (1998), que utilizou imagens para quantificar a ocorrência de patógenos em sementes de soja e milho.

O comportamento apresentado pelas plântulas na figura 1 para ambas as cultivares pode ser representado por uma equação quadrática ,tanto para hipocótilo como para raiz. Esta figura mostra, para a letra A, B, C, D e E plântulas formadas sob temperaturas de $10,15,20,25 \mathrm{e}$ $30^{\circ} \mathrm{C}$ respectivamente, ficando evidenciado prejuízo sob o ponto de vista do crescimento, para as plântulas nas menores temperaturas $\left(10\right.$ e $\left.15^{\circ} \mathrm{C}\right)$. Nas temperaturas de 20 e $25^{\circ}$ $\mathrm{C}$ o desempenho das plantas foi superior, ficando situados nessa faixa os melhores resultados para comprimento do hipocótilo e da raiz. Na temperatura de $30^{\circ} \mathrm{C}$ os resultados de comprimento apresentaram decréscimo, evidenciando possíveis efeitos negativos das altas temperaturas, fazendo com que a ocorrência de plântulas anormais fosse elevada. De acordo com MIGUEL \& CÍCERO (1999), os efeitos da baixa temperatura e do período de exposição a baixas temperaturas são tanto maiores quanto menor for o vigor do lote de sementes, da mesma forma que períodos de altas temperaturas tendem a provocar redução do número de plântulas normais.

Quando é analisado o comportamento médio dos lotes, para comprimento do hipocótilo e da raiz, nas diferentes temperaturas, para os dois métodos (avaliação de imagens digitais e tradicional de laboratório) e para as duas cultivares, observam-se comportamentos quadráticos semelhantes (figura 2), onde a maior e as menores temperaturas provocaram prejuízo ao crescimento das plântulas.

FIGURA 2. Comprimento do hipocótilo para a cultivar Valente (A) e Uirapuru (B) e comprimento da raiz para a cultivar Valente (C) e Uirapuru (D), avaliadas pelo método padrão de laboratório. Comprimento do hipocótilo para a cultivar Valente (E) e Uirapuru (F) e comprimento da raiz para a cultivar Valente (G) e Uirapuru (H), avaliadas pelo método de imagens digitais. Santa Maria/RS, 2006.
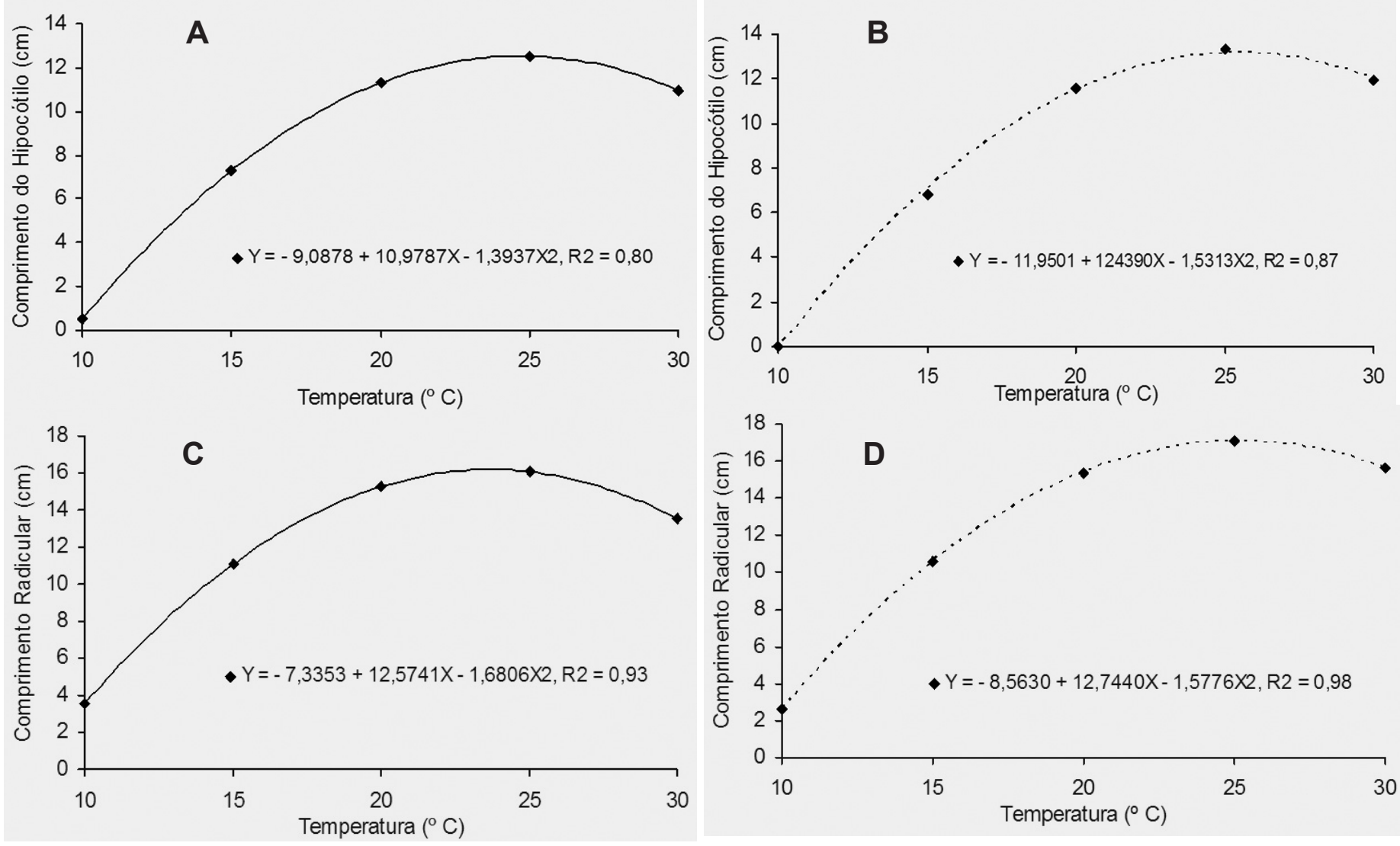

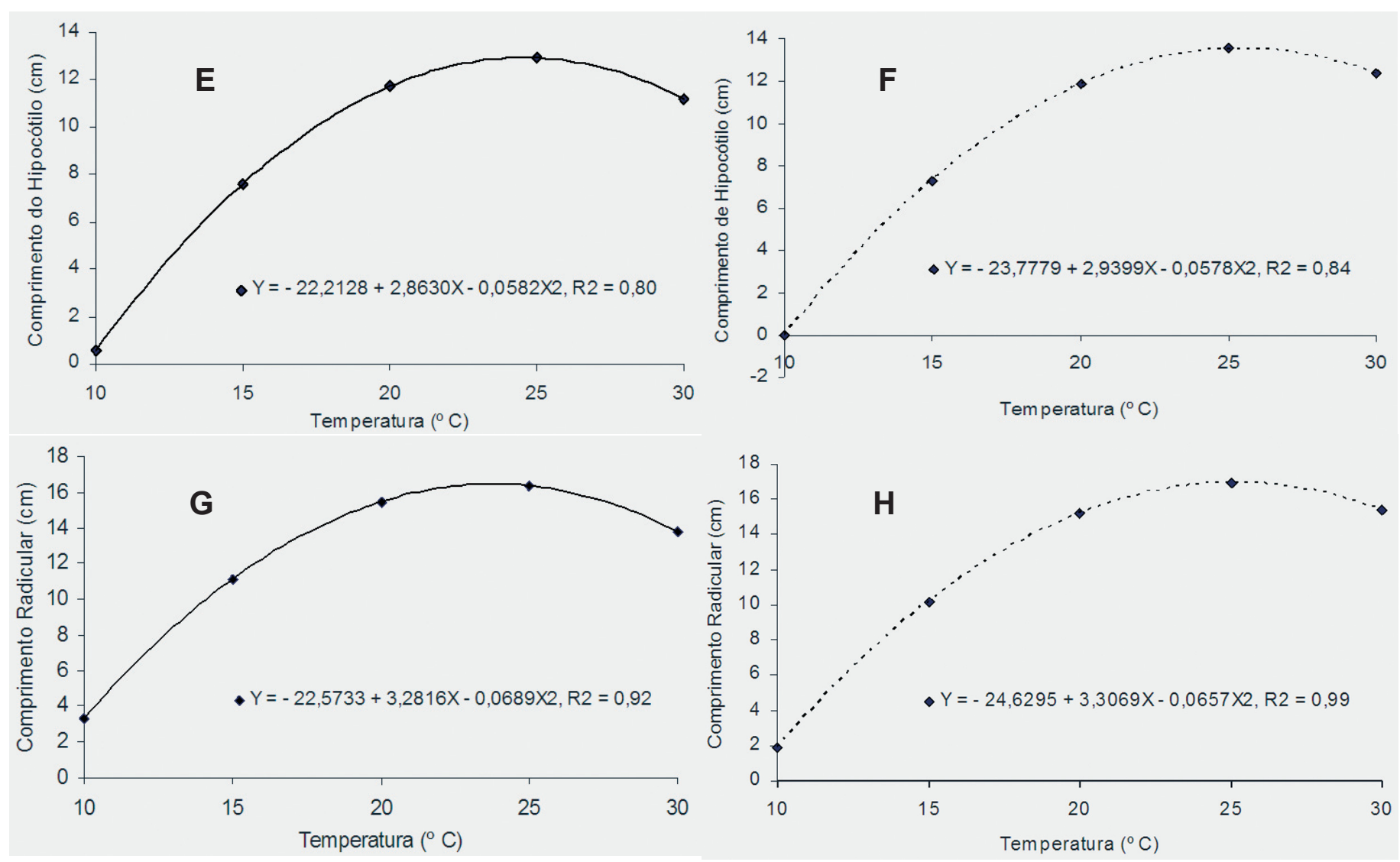

$\mathrm{Na}$ comparação entre as cultivares, do o método tradicional, para avaliação do comprimento do hipocótilo, o comportamento de 'Valente' (figura 2A) e 'Uirapuru' (figura 2B) apresentaram o maior comprimento a $25^{\circ} \mathrm{C}$, o menor comprimento na temperatura de $10^{\circ} \mathrm{C}$ (sendo que a cultivar Uirapuru, não apresentou hipocótilo), e para $30^{\circ} \mathrm{C}$ uma tendência de decréscimo. Para comprimento de raiz (figura 2), a menor temperatura se associou ao menor comprimento de raiz em ambas cultivares, porém para 'Valente' (figura $2 \mathrm{C}$ ), o valor de comprimento de raiz foi superior a 'Uirapuru' (figura 2D). Os maiores valores para comprimento da raiz primária em plântulas de 'Valente' ocorreram entre as temperaturas de 20 e $25^{\circ} \mathrm{C}$, enquanto, para 'Uirapuru', isto se verificou sob a influência de $25^{\circ} \mathrm{C}$. Na maior temperatura testada $\left(30^{\circ} \mathrm{C}\right)$ foi observado decréscimo nos valores de comprimento da raiz.

Para o método através de imagens digitais o comportamento foi semelhante, para 'Valente' (figura 2E) e 'Uirapuru' (figura2F), para comprimento de hipocótilo e raiz (figuras $2 \mathrm{G}$ e $2 \mathrm{H}$ ). Para a cultivar Valente, na variável comprimento de hipocótilo (figura $2 \mathrm{~A}$ e $2 \mathrm{E}$ ), a avaliação de imagens e o método tradicional apresentaram resultados similares e coeficientes de determinação muito próximos

$\left(\mathrm{R}^{2}=0,80\right)$. Para a cultivar Uirapuru (figura $2 \mathrm{~B}$ e $\left.2 \mathrm{~F}\right)$, para a mesma variável, o comportamento e o coeficiente de determinação $\left(\mathrm{R}^{2}=0,87\right.$ e $\left.\mathrm{R}^{2}=0,84\right)$ são semelhantes. Para o comprimento de raiz, tanto 'Valente' (figura $2 \mathrm{C}$ e $2 \mathrm{G}$ ) como 'Uirapuru' (figura 2D e 2H) apresentaram semelhança entre os métodos, sendo os coeficientes de determinação $\mathrm{R}^{2}=0,93,0,92,0,98$ e 0,99 para as figuras $2 \mathrm{C}, 2 \mathrm{G}, 2 \mathrm{D}$ e $2 \mathrm{H}$, respectivamente. Segundo BARROS et al. (1992), as comparações entre análises de laboratório para estas características podem ficar prejudicadas, principalmente, em função de variações no tempo de duração do procedimento, sendo que modificações no teor de água de plântulas ou a morosidade da leitura poderiam interferir no resultado. Já TEIXEIRA (2004), verificou que os dados referentes à análise de imagens digitalizadas corroboraram os obtidos na avaliação tradicional quanto à mensuração de partes de plântulas de milho, determinando o vigor dos lotes utilizados.

Os testes para comprimento de hipocótilo (tabela 1), mostram o comportamento dos testes por meio do processamento das imagens das plântulas e o método tradicional, para cada uma das cultivares, em todas as temperaturas. 
TABELA 1. Comprimento do hipocótilo (cm), para as cultivares Uirapuru e Valente, analisado por de imagens digitais e método tradicional de laboratório, para quatro lotes, em diferentes temperaturas. Santa Maria/RS, 2006.

\begin{tabular}{|c|c|c|c|c|}
\hline & \multicolumn{2}{|c|}{ 'Uirapuru' } & \multicolumn{2}{|c|}{ 'Valente' } \\
\hline & Imagem & Tradicional & Imagem & Tradicional \\
\hline & \multicolumn{4}{|c|}{$10^{\circ} \mathrm{C}$} \\
\hline Lote 1 & $1,05 \mathrm{c}^{*}$ & $0,00 \mathrm{~b}$ & $1,97 \mathrm{a}$ & $1,82 \mathrm{a}$ \\
\hline Lote 2 & $1,20 \mathrm{bc}$ & $0,00 \mathrm{~b}$ & $1,67 \mathrm{~b}$ & $1,55 \mathrm{ab}$ \\
\hline Lote 3 & $1,29 \mathrm{~b}$ & $0,00 \mathrm{~b}$ & $1,65 \mathrm{~b}$ & $1,56 \mathrm{ab}$ \\
\hline \multirow{2}{*}{ Lote 4} & $1,52 \mathrm{a}$ & $1,34 \mathrm{a}$ & $1,67 \mathrm{~b}$ & $1,44 \mathrm{~b}$ \\
\hline & \multicolumn{4}{|c|}{$15^{\circ} \mathrm{C}$} \\
\hline Lote 1 & $3,83 \mathrm{a}$ & $3,48 \mathrm{ab}$ & $4,38 \mathrm{a}$ & $4,22 \mathrm{a}$ \\
\hline Lote 2 & $3,83 \mathrm{a}$ & $3,62 \mathrm{a}$ & $4,18 \mathrm{a}$ & $3,81 \mathrm{a}$ \\
\hline Lote 3 & $3,70 \mathrm{a}$ & $3,37 \mathrm{ab}$ & $4,16 \mathrm{a}$ & $3,88 \mathrm{a}$ \\
\hline \multirow[t]{2}{*}{ Lote 4} & $2,96 \mathrm{a}$ & $2,70 \mathrm{~b}$ & $4,13 \mathrm{a}$ & $4,22 \mathrm{a}$ \\
\hline & \multicolumn{4}{|c|}{$20^{\circ} \mathrm{C}$} \\
\hline Lote 1 & $14,92 \mathrm{a}$ & $12,89 \mathrm{~b}$ & $16,12 \mathrm{a}$ & $15,43 \mathrm{a}$ \\
\hline Lote 2 & $14,79 \mathrm{a}$ & $14,58 \mathrm{a}$ & $15,89 \mathrm{a}$ & $15,58 \mathrm{a}$ \\
\hline Lote 3 & $13,97 \mathrm{ab}$ & $14,45 \mathrm{~b}$ & $14,76 a b$ & $14,45 a b$ \\
\hline \multirow[t]{2}{*}{ Lote 4} & $13,56 \mathrm{~b}$ & $13,12 \mathrm{~b}$ & $13,01 \mathrm{~b}$ & $12,52 \mathrm{~b}$ \\
\hline & \multicolumn{4}{|c|}{$25^{\circ} \mathrm{C}$} \\
\hline Lote 1 & $14,20 \mathrm{a}$ & $12,74 \mathrm{a}$ & $12,90 \mathrm{a}$ & $12,12 \mathrm{a}$ \\
\hline Lote 2 & $13,91 \mathrm{a}$ & $13,87 \mathrm{a}$ & $12,70 \mathrm{a}$ & $12,89 \mathrm{a}$ \\
\hline Lote 3 & $14,92 \mathrm{a}$ & $14,28 \mathrm{a}$ & $12,15 \mathrm{a}$ & $11,27 \mathrm{ab}$ \\
\hline \multirow[t]{2}{*}{ Lote 4} & $13,82 \mathrm{a}$ & $14,63 \mathrm{a}$ & $10,34 \mathrm{~b}$ & $9,84 \mathrm{~b}$ \\
\hline & \multicolumn{4}{|c|}{$30^{\circ} \mathrm{C}$} \\
\hline Lote 1 & $10,86 \mathrm{a}$ & $10,15 \mathrm{a}$ & $11,94 \mathrm{a}$ & $11,36 \mathrm{a}$ \\
\hline Lote 2 & $11,86 \mathrm{a}$ & $11,51 \mathrm{a}$ & $11,98 \mathrm{a}$ & $12,57 \mathrm{a}$ \\
\hline Lote 3 & $12,84 \mathrm{a}$ & $12,59 \mathrm{a}$ & $11,32 \mathrm{a}$ & $10,89 a b$ \\
\hline Lote 4 & $11,19 \mathrm{a}$ & $10,97 \mathrm{a}$ & $9,23 \mathrm{~b}$ & $8,89 \mathrm{~b}$ \\
\hline MÉDIA & 9,01 & 8,51 & 8,80 & 8,51 \\
\hline C.V. $(\%)$ & 8,16 & 9,46 & 7,86 & 9,32 \\
\hline
\end{tabular}

*Médias não seguidas pela mesma letra, na coluna, para cada temperatura, diferem entre si pelo Teste de Tukey a 5\% de probabilidade de erro.

De maneira geral, para todos os casos, não houve variações acentuadas na discriminação do desempenho dos lotes e, em todos os casos, a hierarquia de "qualidade" dos lotes foi mantida para ambos os métodos. Em função da precisão dos dados para cada lote e da sensibilidade do teste estatístico para cada método, em uma ou outra situação, o teste apontou diferenças discriminadas quando analisados os comportamentos entre os métodos.

$\mathrm{Na}$ análise dos resultados da tabela 1 , observam-se três comportamentos para a distribuição das médias dos lotes na comparação entre os métodos. Para a cultivar Uirapuru, nas temperaturas de 25 e $30^{\circ} \mathrm{C}$ e, para 'Valente', nas temperaturas de 15 e $20^{\circ} \mathrm{C}$, os resultados foram semelhantes para os dois métodos. Nas temperaturas de 10 e $20^{\circ} \mathrm{C}$ para 'Uirapuru' e
10,25 e $30^{\circ} \mathrm{C}$ para 'Valente', verificou-se que a identificação dos melhores e dos piores lotes foi mantida, embora existam algumas divergências estatísticas na qualificação dos demais lotes. Na comparação entre os métodos, para a cultivar Uirapuru, na temperatura de $15^{\circ} \mathrm{C}$, os resultados para cada teste foi distinto, não havendo diferença entre lotes, segundo o método de análise imagens, enquanto que para o método tradicional, o lote 2 foi superior ao lote 4 e este foi inferior ao lote 2. Pequenas diferenças nas condições controladas do ambiente em laboratório podem ocasionar mudanças nas avaliações realizadas, como por exemplo, a temperatura, sendo que estas, sensíveis diferenças na temperatura de crescimento, podem afetar significativamente o comprimento da raiz e do hipocótilo, de acordo com PERRY (1981). 
As médias dos lotes e temperaturas para cada cultivar apresentaram variações. Para 'Uirapuru', 9,01 e 8,51 cm e para 'Valente' 8,80 e $8,51 \mathrm{~cm}$, para análise de imagens e tradicional de laboratório, respectivamente, mostrando que o método tradicional tende a subestimar a média em relação ao método de processamento de imagens. Para os coeficientes de variação, foram verificadas diferenças pouco acentuadas entre os métodos, sendo para ambas as cultivares os menores valores para o método das imagens digitais.
Na tabela 2 estão expressos os valores de comprimento de raiz para os lotes, cultivares, métodos e temperaturas utilizadas no trabalho. Para a cultivar Uirapuru nas temperaturas de 20, 25 e $30^{\circ} \mathrm{C}$ e para 'Valente' nas temperaturas de $10,15,25$ e $30^{\circ} \mathrm{C}$, os resultados foram semelhantes para os dois métodos de avaliação de plântulas. Nos demais casos verificouse que a identificação dos melhores e dos piores lotes foi mantida, embora existam algumas divergências estatísticas na qualificação dos demais lotes.

TABELA 2. Comprimento da raiz (cm), para as cultivares Uirapuru e Valente, analisado por imagens digitais e método tradicional de laboratório, para quatro lotes, em diferentes temperaturas. Santa Maria/RS, 2006.

\begin{tabular}{|c|c|c|c|c|}
\hline & \multicolumn{2}{|c|}{ 'Uirapuru' } & \multicolumn{2}{|c|}{ 'Valente' } \\
\hline & Imagem & Tradicional & Imagem & Tradicional \\
\hline & \multicolumn{4}{|c|}{$10^{\circ} \mathrm{C}$} \\
\hline Lote 1 & $1,17 \mathrm{c}$ & $2,10 \mathrm{~b}$ & $4,85 \mathrm{a}$ & $5,03 \mathrm{a}$ \\
\hline Lote 2 & $1,15 \mathrm{bc}$ & $2,88 \mathrm{a}$ & $3,25 \mathrm{~b}$ & $3,22 \mathrm{~b}$ \\
\hline Lote 3 & $2,06 \mathrm{~b}$ & $3,34 \mathrm{a}$ & $3,18 \mathrm{~b}$ & $3,23 \mathrm{~b}$ \\
\hline \multirow[t]{2}{*}{ Lote 4} & $3,32 \mathrm{a}$ & $3,51 \mathrm{a}$ & $2,79 \mathrm{~b}$ & $2,95 \mathrm{~b}$ \\
\hline & \multicolumn{4}{|c|}{$15^{\circ} \mathrm{C}$} \\
\hline Lote 1 & $10,62 \mathrm{a}$ & $10,46 \mathrm{a}$ & $10,46 \mathrm{a}$ & $10,87 \mathrm{a}$ \\
\hline Lote 2 & $9,71 \mathrm{a}$ & $9,96 \mathrm{ab}$ & $10,35 \mathrm{a}$ & $10,52 \mathrm{a}$ \\
\hline Lote 3 & $9,57 \mathrm{a}$ & $9,69 \mathrm{ab}$ & $10,24 \mathrm{a}$ & $10,30 \mathrm{a}$ \\
\hline \multirow[t]{2}{*}{ Lote 4} & $8,09 \mathrm{~b}$ & $8,34 \mathrm{~b}$ & $9,13 \mathrm{a}$ & $9,52 \mathrm{a}$ \\
\hline & \multicolumn{4}{|c|}{$20^{\circ} \mathrm{C}$} \\
\hline Lote 1 & $17,45 \mathrm{a}$ & $16,47 \mathrm{ab}$ & $19,53 \mathrm{a}$ & $19,20 \mathrm{a}$ \\
\hline Lote 2 & $17,45 \mathrm{a}$ & $18,54 \mathrm{a}$ & $18,77 \mathrm{ab}$ & $18,42 \mathrm{a}$ \\
\hline Lote 3 & $15,23 \mathrm{ab}$ & $16,20 \mathrm{ab}$ & $17,38 \mathrm{~b}$ & $17,03 \mathrm{ab}$ \\
\hline \multirow[t]{2}{*}{ Lote 4} & $13,38 \mathrm{~b}$ & $13,04 \mathrm{~b}$ & $14,72 \mathrm{c}$ & $13,79 \mathrm{~b}$ \\
\hline & \multicolumn{4}{|c|}{$25^{\circ} \mathrm{C}$} \\
\hline Lote 1 & $17,14 \mathrm{a}$ & $17,55 \mathrm{a}$ & $16,24 \mathrm{a}$ & $15,70 \mathrm{a}$ \\
\hline Lote 2 & $16,86 \mathrm{a}$ & $17,05 \mathrm{a}$ & $14,72 \mathrm{ab}$ & $14,45 \mathrm{ab}$ \\
\hline Lote 3 & $16,83 \mathrm{a}$ & $17,93 \mathrm{a}$ & $14,72 \mathrm{ab}$ & $14,02 \mathrm{ab}$ \\
\hline \multirow[t]{2}{*}{ Lote 4} & $16,00 \mathrm{a}$ & $16,49 \mathrm{a}$ & $12,54 \mathrm{~b}$ & $11,99 \mathrm{~b}$ \\
\hline & \multicolumn{4}{|c|}{$30^{\circ} \mathrm{C}$} \\
\hline Lote 1 & $17,26 \mathrm{a}$ & $17,55 \mathrm{a}$ & $16,69 \mathrm{a}$ & $16,73 \mathrm{a}$ \\
\hline Lote 2 & $16,25 \mathrm{ab}$ & $16,34 \mathrm{ab}$ & $14,57 \mathrm{ab}$ & $14,43 \mathrm{ab}$ \\
\hline Lote 3 & $17,41 \mathrm{~b}$ & $14,19 \mathrm{~b}$ & $13,52 \mathrm{~b}$ & $13,27 \mathrm{~b}$ \\
\hline Lote 4 & $13,85 \mathrm{~b}$ & $13,72 \mathrm{~b}$ & $12,53 \mathrm{~b}$ & $11,82 \mathrm{~b}$ \\
\hline MÉDIA & 11,91 & 12,09 & 12,01 & 11,28 \\
\hline C.V. $(\%)$ & 10,05 & 11,04 & 8,42 & 10,88 \\
\hline
\end{tabular}

*Médias não seguidas pela mesma letra, na coluna, para cada temperatura, diferem entre si pelo Teste de Tukey a $5 \%$ de probabilidade de erro.

Nas avaliações das médias gerais, para a cultivar Uirapuru, os métodos de imagens digitais e tradicional de laboratório apresentaram valores de comprimento de raiz muito próximos (11,91 cm e 12,09 $\mathrm{cm}$, respectivamente) e para 'Valente' a maior média foi observada para o método das imagens digitais $(12,01 \mathrm{~cm}$ contra 11,28 cm). Os coeficientes 
de variação (C.V.\%) foram inferiores para o método das imagens digitais, sendo 10,05 e 8,42 \%, para 'Uirapuru' e 'Valente', respectivamente. TEIXEIRA (2004), comparando os métodos de imagens digitais e o método tradicional verificou as mesmas repostas estatísticas e de diferenças de vigor entre lotes de qualidades fisiológicas distintas.

Na tabela 3, observamos o resultado das correlações entre os métodos e as variáveis analisadas, para todas as temperaturas, onde todas as correlações foram significativas. Para as duas cultivares, a relação entre os métodos e variáveis foi alta (superior a 0,93). As correlações entre comprimento do hipocótilo e raiz foram significativas, o que permitiu a mensuração de somente uma das variáveis, para observação do vigor em cada uma das situações testadas (diferentes lotes e temperaturas). O novo método (imagens digitais) tem alta relação com o tradicional, sendo menos trabalhoso que este, uma vez que se permite captar um volume maior de informações (neste caso, imagens) em menor tempo, e analisá-las posteriormente.

TABELA 3. Correlações entre o método de imagens digitais (Im.) e método tradicional de laboratório (Trad.) para as variáveis: comprimento do hipocótilo $(\mathrm{CH})$ e comprimento da raiz $(\mathrm{CR})$ para as cultivares Uirapuru e Valente. Santa Maria/RS, 2006.

\begin{tabular}{lcccc}
\hline & Im. - CH & Trad. - CH & Im. - CR & Trad. - CR \\
\cline { 2 - 5 } & \multicolumn{4}{c}{ 'Uirapuru' } \\
\hline Im. - CH & - & 0,993 & 0,930 & 0,935 \\
Trad. - CH & 0,993 & - & 0,933 & 0,938 \\
Im. - CR & 0,930 & 0,933 & - & 0,986 \\
Trad. - CR & 0,935 & 0,938 & 0,986 & - \\
\hline & \multicolumn{5}{c}{0,938} \\
Im. - CH & - & 'Valente' & 0,9357 \\
Trad. - CH & 0,998 & 0,998 & 0,953 & 0,998 \\
Im. - CR & 0,953 & - & 0,941 & - \\
Trad. - CR & 0,938 & 0,949 & 0,998 & - \\
\hline
\end{tabular}

\section{CONCLUSÕES}

As avaliações de crescimento de plântulas, por meio de análise de imagens digitais e pelo método tradicional, apresentam resultados semelhantes e são eficientes para a avaliação do vigor de sementes de feijão.

\section{REFERÊNCIAS}

BARROS, A.S.R.B.; DIAS, M.C.L.L.; CICERO, S.M.; KRZYZANOWSKI, F.C. Teste de frio. In: KRZYZANOWSKI, F.C.; VIEIRA, R.D.; FRANÇA NETO, J.B. (Ed.). Vigor de sementes: conceitos e testes. Londrina: ABRATES, 1999. p.1-15.

BRASIL. Ministério da Agricultura e da Reforma Agrária. Regras para análise de sementes. Brasília, DF: SNDA/ DNDV/CLAV, 1992. 365p.
CUSTÓDIO, C.C. Testes rápidos para avaliação do vigor de sementes: uma revisão. Colloquium Agrariae, Presidente Prudente, v.1, n.1, p.29-41, 2005.

GUNASEKARAN, S. et al. Evaluating quality factors of corn and soybean using a computer vision system: Transactions of the ASE. American Society of Agricultural Engineers. Saint Joseph, v.36, p.1937-1940, 1993.

JAUER, A. et al. Análise de crescimento do cultivar de feijão Iraí em quatro densidades de semeadura. Pesquisa Agropecuária Gaúcha, Porto Alegre, v.10, n.1-2, p.23-33, 2004.

MARCOS FILHO, J. Teste de envelhecimento acelerado. In: VIEIRA, R.D.; CARVALHO, N.M. (Ed.). Testes de vigor em sementes. Jaboticabal: FUNEP, 1994. p.133-149.

MIGUEL, M.H.; CÍCERO, S.M. Teste de frio na avaliação do vigor de sementes de feijão. Scientia Agricola. Piracicaba, 
v.56, n.4, p.1233-1243, 1999.

NAKAGAWA, J. Testes de vigor baseados na avaliação de plântulas. In: VIEIRA, R.D.; CARVALHO, N.M. (Ed.). Testes de vigor em sementes. Jaboticabal: FUNEP, 1994. p.49-86.

PERRY, D.A. Report of the Vigour Test Committee. Seed Science \& Technology, Zürich, v.9, n.1, p.115-128, 1981.

ROEGGEN, O. Variation in minimum germination temperature for cultivars of bean (Phaseolus vulgaris L.) and tomato (Lycopersicon esculentum Mill). Scientia Horticultural, Amsterdam, v.33, p.57-65, 1987.

SIQUEIRA, E.C. Avaliação da embebição e do comportamento da germinação de sementes de cultivares de feijão (Phaseolus vulgaris L.) em baixa temperatura. Ciência e Prática, Lavras, v.19, n.4, p.351-356, 1995.

STORCK, L. et al. Experimentação II. 2 ed. Santa Maria:
UFSM, CCR, Departamento de Fitotecnia, 2006. 205p.

TEIXEIRA, E.F. Análise de imagens digitais na avaliação de plântulas de milho. 2004. 57f. Tese (Doutorado em Agronomia) - Escola Superior de Agricultura Luiz de Queiroz, Universidade de São Paulo, Piracicaba.

VOOREN, J.G.; HEIJDEN G.W.A.M. Measuring the size of french beans with image analysis. Plant Varieties and Seed, Defra, v.36, n.6, p.1937-1940, 1993.

ZABOT, L. et al.. Análise de crescimento da cultivar de feijão BR IPAGRO 44 Guapo Brilhante cultivada na safrinha, em quatro densidades de semeadura, em Santa Maria/RS. Revista de Ciências Agroveterinárias, Lages, v.3, n.2, p.105-115, 2004.

ZONTA, E.P.; MACHADO, A.A. Sistema de análise estatística para microcomputadores - SANEST. Pelotas: UFPel, Instituto de Física e Matemática, 1986. 150p. 